\title{
0512 SAFE PRODUCT DESIGN (SAF-D-PRO) CERTIFICATION
} SCHEME

G Rider, M Inman, E Nielsen, J Reilly, J Vincenten, P Hakkinen, R Reiss, R Easton, $X$ Chen, G Emerson* Correspondence: Intertek, Phoenix Yard 69 King's Cross Road, London WC1X 9LN, UK

\subsection{6/ip.2010.029215.512}

Consumer product safety is vital in our daily lives. Driven by recent recalls, regulatory authorities around the globe are strengthening its requirements and enforcement in order to regain confidence among consumers. Historically, approximately two-thirds of recalls were the result of design defects. Robust design appraisal as a remedy for the root causes of product recalls has received significant attention. Nonetheless, there has been a lack of governance and standardisation for design appraisals. As a result, RABOSA International, a recognised leader in designing, developing, and delivering accredited personnel and training certification services, has moved forward with an initiative to develop a competencybased personnel certification program for Consumer Product Design Safety Assessment (CPDSA). An international multistakeholder steering committee was formed to develop a personnel certification scheme for design appraisers of consumer products through incorporating the best techniques and practices available. Six elements of competency were identified: (1) market place product entry requirements; (2) data analysis; (3) foreseeable use; (4) Engineering, chemical, and (micro)biological analyses; (5) human factors; (6) product characteristics. A skill examination was developed based on these six elements to assess the practical competency of applicants. This initiative paves the way for future development of a certification scheme for consumer product risk analysts. 